CLINICAL STUDY

\title{
Nonalcoholic fatty liver disease in adult hypopituitary patients with GH deficiency and the impact of GH replacement therapy
}

Hitoshi Nishizawa, Genzo Iguchi, Ayumi Murawaki, Hidenori Fukuoka, Yoshitake Hayashi ${ }^{1}$, Hidesuke Kaji ${ }^{2}$, Masaaki Yamamoto, Kentaro Suda, Michiko Takahashi, Yasushi Seo ${ }^{3}$, Yoshihiko Yano ${ }^{3}$, Riko Kitazawa ${ }^{4}$, Sohei Kitazawa $^{4}$, Masafumi Koga ${ }^{5}$, Yasuhiko Okimura ${ }^{6}$, Kazuo Chihara ${ }^{7}$ and Yutaka Takahashi

Division of Diabetes and Endocrinology, Department of Internal Medicine, Kobe University Graduate School of Medicine, 7-5-1, Kusunoki-cho, Chuo-ku, Kobe 650-0017, Japan, ${ }^{1}$ Division of Molecular Medicine and Medical Genetics, Department of Pathology, Kobe University Graduate School of Medicine, Kobe, Japan, ${ }^{2}$ Division of Physiology/Metabolism, University of Hyogo, Akashi, Japan, ${ }^{3}$ Department of Gastroenterology, Kobe University Graduate School of Medicine, Kobe, Japan, ${ }^{4}$ Division of Molecular Pathology, Ehime University Graduate School of Medicine, Ehime, Japan, ${ }^{5}$ Department of Internal Medicine, Kinki Central Hospital, Itami, Japan, ${ }^{6}$ Department of Nutrition and Food Science, Kobe Women's University, Kobe, Japan and ${ }^{7}$ Hyogo Prefectural Kakogawa Medical Center, Kakogawa, Japan

(Correspondence should be addressed to Y Takahashi; Email: takahash@med.kobe-u.ac.jp)

\begin{abstract}
Background: Liver dysfunction in adult hypopituitary patients with GH deficiency (GHD) has been reported and an increased prevalence of nonalcoholic fatty liver disease (NAFLD) has been suggested. Objective: The objective of the present study was to elucidate the pathophysiology of the liver in adult hypopituitary patients with GHD.

Patients and methods: We recruited 69 consecutive Japanese adult hypopituitary patients with GHD and examined the prevalence of NAFLD by ultrasonography and nonalcoholic steatohepatitis (NASH) by liver biopsy. Patients had been given routine replacement therapy except for GH. We compared these patients with healthy age-, gender-, and BMI-matched controls. We further analyzed the effect of GH replacement therapy on liver function, inflammation and fibrotic markers, and histological changes. Results: The prevalence of NAFLD in hypopituitary patients with GHD was significantly higher than in controls $(77$ vs $12 \%, P<0.001)$. Of 16 patients assessed by liver biopsy, $14(21 \%)$ patients were diagnosed with NASH. GH replacement therapy significantly reduced serum liver enzyme concentrations in the patients and improved the histological changes in the liver concomitant with reduction in fibrotic marker concentrations in patients with NASH.

Conclusions: Adult hypopituitary patients with GHD demonstrated a high NAFLD prevalence. The effect of GH replacement therapy suggests that the NAFLD is predominantly attributable to GHD.
\end{abstract}

European Journal of Endocrinology 167 67-74

\section{Introduction}

Adult GH deficiency (GHD) is characterized by increased visceral adiposity, decreased lean body mass, and abnormal lipid profile (1). On the other hand, patients with hypothalamic and pituitary dysfunction display weight gain, insulin resistance, and dyslipidemia with subsequent development of nonalcoholic fatty liver disease (NAFLD) (2). Several reports have suggested that such hepatic impairment may be particularly related to GHD. For instance, adult hypopituitarism with GHD has been reported to be associated with liver dysfunction and hyperlipidemia $(3,4)$. Ichikawa et al. (5) showed that hepatic steatosis was more frequently observed in hypopituitary patients with GHD than in patients without GHD, with hepatic steatosis present in $54 \%$ of the patients with GHD. In another case of adult hypopituitary patients with GHD accompanied by nonalcoholic steatohepatitis (NASH) and hyperlipidemia, we reported that $\mathrm{GH}$ replacement therapy drastically reversed NASH (6). Moreover, the severity of fatty liver was shown to be related to hypopituitary patients' GH levels (7). Interestingly, in the non-GH-deficient population, $\mathrm{GH}$, insulin-like growth factor 1 (IGF1), and IGF-binding protein 3 were associated with hepatic fibrosis and steatosis in NAFLD (8), suggesting that the GH-IGF1 axis may play an important role in the liver in the physiological condition. These data strongly suggest an association between GHD and NAFLD/NASH (9), although the precise relationship remains to be elucidated.

NAFLD includes both nonalcoholic fatty liver and NASH. NAFLD can be diagnosed by detecting the steatosis in the liver using imaging techniques including ultrasonography, computed tomography (CT), and magnetic resonance imaging (MRI) (10). The diagnosis of NASH is based on pathohistological findings obtained by liver biopsy. NASH is a progressive 
disease characterized by steatosis, inflammatory infiltration, hepatocyte injury, and fibrosis. The progression to NASH seems to be associated with multiple factors, but it generally consists of two steps: first, the insulin resistance in conjunction with an accumulation of fat in visceral adipose tissue and within hepatocytes; and second, the increased oxidative stress, cytokine induction, and inflammation (11). Interestingly, a series of pathological cascade is comparable with the findings observed in adult patients with GHD, and GH replacement therapy improves these conditions, suggesting a common pathological background between NAFLD and adult GHD (12).

To clarify the association between GHD and NAFLD/ $\mathrm{NASH}$, we performed a clinical study in Japanese hypopituitary patients with GHD.

\section{Materials and methods}

\section{Patients}

This study was approved by the Kobe University Graduate School of Medicine Ethics Committee and the Kinki Central Hospital Ethics Committee. Written informed consent was obtained from all participants. We included 69 consecutive adult hypopituitary patients with GHD diagnosed and assessed between January 2002 and November 2010 in the Division of Diabetes and Endocrinology, the Kobe University Hospital, and analyzed in a retrospective and crosssectional design. For the diagnosis of adult GHD, each patient was subjected to an insulin tolerance test (13) or the GH releasing peptide-2 test (14). The hypothalamopituitary-adrenal axis, hypothalamo-pituitary-thyroid axis, and hypothalamo-pituitary-gonadal axis were evaluated as previously described (15). We excluded hypopituitary patients with acromegaly or Cushing's disease. For the control group, we enrolled 1994 control subjects (1278 men and 716 women) who underwent a health check-up at Kinki Central Hospital between May and October 2006. Among these subjects, 83 age-, gender-, and BMI-matched subjects were randomly selected for comparison with the GHD group. Exclusion criteria for both GHD and control subjects included alcohol consumption of more than $20 \mathrm{~g} /$ day for women and more than $30 \mathrm{~g} /$ day for men. Subjects were also excluded if they had cirrhosis, hepatitis B or C, other liver diseases, or if they were receiving drugs known to cause steatohepatitis (16).

\section{Study design}

NAFLD was diagnosed based on the results of ultrasonography, which is the most common method employed for assessment of hepatic steatosis (17). The presence of intrahepatic fat was assessed by an ultrasonographic scan using a Siemens ALOKA system with a $3.5 \mathrm{MHz}$ transducer (ALOKA, Tokyo, Japan). Detection of hepatic fat was based on an echogenic parenchyma (in relation to the right kidney), posterior attenuation and the presence of focal fatty sparing $(18,19)$. All of the images were assessed at the end of the study by a physician blinded to the clinical history. The diagnosis of NASH was confirmed by a liver biopsy according to the standard clinical indication for liver disease (20). We examined patients by liver biopsy, who showed liver dysfunction, NAFLD in ultrasonography, and agreed with further examination by biopsy with written informed consent. Liver biopsy specimens were evaluated independently by two pathologists blinded to the patients' clinical histories. Disease activity was assessed using the NAFLD activity score (21). The metabolic variables were determined using standard methods with the use of automated equipment (Hitachi).

\section{GH replacement therapy}

GH replacement therapy was performed in the patients who agreed to treatment, according to the general guidelines for the treatment of adult GHD (13). Patients receiving other medical therapies including corticosteroid, L-thyroxine, and sex steroids for replacement, as well as antidyslipidemic and antihypertensive agents, continued to receive them in the same doses for at least 6 months prior to and then during their $\mathrm{GH}$ replacement therapy.

\section{Data analysis}

Results are expressed as the mean \pm s.D. unless otherwise specified. Statistical analysis was performed using JMP Statistical Database Software (SAS Institute, Inc., Cary, NC, USA). The data were analyzed using $\chi^{2}$ (or Fisher's exact) test, two-sample $t$-test, paired $t$-test, two-way ANOVA followed by Tukey's post hoc test, and Wilcoxon signed-rank test as appropriate. Statistical significance was set at $P<0.05$.

\section{Results}

\section{The prevalence of NAFLD/NASH in adult hypopituitary patients with GHD}

To clarify the prevalence of NAFLD/NASH in adult hypopituitary with GHD, we analyzed 69 consecutive Japanese patients and compared them with healthy age-, gender-, and BMI-matched control subjects. The patients had been given routine replacement therapy except for GH. In the GHD group, one with active hepatitis B and two with alcoholic hepatitis were excluded from this study. Thus, we subsequently analyzed the remaining 66 patients (with a mean \pm s.e.M., age of $48.1 \pm 2.2$; 32 males, 34 females). Causes of hypopituitarism are shown in Supplementary 
Table 1 Clinical characteristics of adult hypopituitary patients with GHD and age-, gender-, and BMI-matched control subjects. Values are means \pm S.D. BMI is the weight in kilograms divided by the square of the height in meters. The homeostasis model assessment-insulin resistance (HOMA-IR) index was applied to assess insulin resistance from fasting insulin and glucose levels by using the following equation: (insulin $(\mu \mathrm{l} / \mathrm{ml}$ ) glucose $(\mathrm{mmol} / \mathrm{l})) / 22.5(42)$.

\begin{tabular}{|c|c|c|c|}
\hline & $\begin{array}{l}\text { Control } \\
(n=83)\end{array}$ & $\begin{array}{l}\text { GHD } \\
(n=66)\end{array}$ & $P$ value \\
\hline Age (years) & $48.2 \pm 12.0$ & $48.1 \pm 17.8$ & 0.81 \\
\hline $\operatorname{Sex}(M / F)$ & $40 / 43$ & $32 / 34$ & 0.93 \\
\hline BMI & $25.2 \pm 3.5$ & $25.0 \pm 4.9$ & 0.66 \\
\hline $\operatorname{NAFLD~}(n ; \mathrm{M} / \mathrm{F})$ & $10(7 / 3)$ & $51(27 / 24)$ & $<0.001$ \\
\hline NAFLD (\%; M/F) & $12(18 / 7)$ & $77(84 / 71)$ & $\begin{array}{l}\text { M: } \boldsymbol{P}<0.0001 \\
\text { F: } \boldsymbol{P}<0.0001\end{array}$ \\
\hline AST (IU/I) & $21.3 \pm 8.8$ & $39.3 \pm 28.4$ & $<0.0001$ \\
\hline ALT (IU/I) & $24.7 \pm 14.0$ & $41.9 \pm 38.9$ & $<0.0005$ \\
\hline$\gamma$-GTP (IU/I) & $26.9 \pm 16.7$ & $65.0 \pm 116.6$ & $<0.005$ \\
\hline LDL-C (mg/dl) & $126.6 \pm 27.3$ & $130.9 \pm 33.2$ & 0.37 \\
\hline HDL-C (mg/dl) & $57.7 \pm 13.7$ & $54.8 \pm 22.7$ & 0.30 \\
\hline Triglyceride $(\mathrm{mg} / \mathrm{dl})$ & $136.6 \pm 88.8$ & $219.2 \pm 143.4$ & $<0.0001$ \\
\hline $\begin{array}{l}\text { Fasting glucose } \\
(\mathrm{mg} / \mathrm{dl})\end{array}$ & $98.8 \pm 16.9$ & $93.4 \pm 18.6$ & 0.06 \\
\hline Fasting IRI $(\mu \mathrm{U} / \mathrm{ml})$ & $5.96 \pm 2.7$ & $8.23 \pm 6.56$ & $<0.01$ \\
\hline HOMA-IR & $1.47 \pm 0.76$ & $1.93 \pm 1.62$ & $<0.05$ \\
\hline $\mathrm{HbA1c}(\%)$ & $5.32 \pm 0.73$ & $5.27 \pm 0.56$ & 0.65 \\
\hline hs-CRP (ng/ml) & $0.06 \pm 0.05$ & $0.35 \pm 0.32$ & $<0.0001$ \\
\hline
\end{tabular}

Values in bold indicate statistical significance.

Figure 1A, see section on supplementary data given at the end of this article. The prevalence of NAFLD in the control group ( $12 \%$ overall, men $18 \%$, women $7 \%$ ) was comparable with that in the previous report in the Japanese population $(22,23,24)$. Strikingly, the prevalence of NAFLD in the GHD group was significantly increased by 6.4 -fold compared with the control group (77 and $12 \%, P<0.001$; Table 1 ).
In the GHD group, the serum alanine aminotransferase (ALT; $P<0.0001$ ), aspartate aminotransferase (AST; $P<0.0005), \gamma$-glutamyl transferase $(\gamma$-GTP; $P<0.005)$, triglyceride $(P<0.0001)$, and hs-CRP $(P<0.0001)$ levels and fasting IRI $(P<0.01)$ and homeostasis model assessment-insulin resistance (HOMA-IR; $P<0.05$ ) scores were significantly higher than the corresponding levels in the control group (Table 1). We examined 16 patients who showed liver dysfunction and NAFLD in ultrasonography by liver biopsy and found that 14 of the 16 patients had characteristics of NASH (Table 2). Moreover, of the other two patients, the histology of one patient revealed steatohepatitis and that of the other revealed mild fibrosis (Table 2). Because liver biopsy was performed in only a part of the group, it is speculated that the prevalence of NASH in the hypopituitary patients with GHD was estimated to be lower than that of the true one. Nonetheless, the prevalence of NASH in this study $(14 / 66,21 \%)$ was apparently high compared with the prevalence of $1-3 \%$ that was previously reported for the Japanese population $(24,25)$.

\section{The characteristics of NAFLD and NASH in patients with GHD}

The clinical characteristics of NAFLD $(-)$ and $(+)$ in the patients with GHD are shown in Table 3. The profile of causes of hypopituitarism in the NAFLD $(+)$ group was similar to those of the total patients; however, although it was not statistically significant, the NAFLD (-) group showed a different profile that was more predominantly idiopathic, Sheehan's syndrome, and Rathke's cleft cyst and less predominantly craniopharyngioma and pituitary adenoma compared with

Table 2 Clinical characteristics of the study subjects who underwent liver biopsy. Histological examination of the liver was performed before and after $\mathrm{GH}$ replacement therapy in cases $1-5$.

\begin{tabular}{|c|c|c|c|c|c|c|}
\hline Case & Age & Sex & Onset & Cause & Liver histology & $\begin{array}{c}\text { Period of GH } \\
\text { treatment } \\
\text { (months) }\end{array}$ \\
\hline 1 & 31 & $M$ & $\mathrm{CO}$ & Invisible stalk & $\mathrm{NASH}$ & 6 \\
\hline 2 & 60 & $\mathrm{~F}$ & $\mathrm{AO}$ & Craniopharyngioma & NASH & 12 \\
\hline 3 & 32 & M & $\mathrm{CO}$ & Meningioma & NASH & 12 \\
\hline 4 & 41 & $\mathrm{M}$ & $\mathrm{CO}$ & Stalk transection & NASH (burn out) & 12 \\
\hline 5 & 56 & M & $\mathrm{AO}$ & Rathke's cleft cyst & NASH & 12 \\
\hline 6 & 51 & M & $\mathrm{AO}$ & Hypothalamic lymphoma & Steatohepatitis & \\
\hline 7 & 72 & $\mathrm{~F}$ & $\mathrm{AO}$ & Hypophysitis & NASH & \\
\hline 8 & 44 & $\mathrm{~F}$ & $\mathrm{AO}$ & Craniopharyngioma & NASH & \\
\hline 9 & 40 & $\mathrm{~F}$ & $\mathrm{AO}$ & Craniopharyngioma & NASH & \\
\hline 10 & 67 & $M$ & $\mathrm{AO}$ & Pituitary adenoma & $\mathrm{NASH}$ & \\
\hline 11 & 64 & M & $\mathrm{AO}$ & Hypophysitis & NASH & \\
\hline 12 & 24 & $\mathrm{~F}$ & $\mathrm{CO}$ & Craniopharyngioma & NASH & \\
\hline 13 & 25 & $\mathrm{~F}$ & $\mathrm{CO}$ & Craniopharyngioma & NASH & \\
\hline 14 & 16 & $\mathrm{~F}$ & $\mathrm{CO}$ & Craniopharyngioma & NASH & \\
\hline 15 & 49 & M & $\mathrm{CO}$ & Pituitary atrophy & Mild fibrosis & \\
\hline 16 & 69 & $\mathrm{~F}$ & $\mathrm{AO}$ & Craniopharyngioma & NASH & \\
\hline
\end{tabular}

$\mathrm{CO}$, child-onset adult GHD; AO, adult-onset GHD. 
Table 3 Clinical characteristics of hypopituitary patients with GHD with or without NAFLD/NASH. Plus-minus values are means \pm s.D. The $P$ values shown are for the comparisons between the NAFLD $(+)$ group or the NASH subgroup and the NAFLD $(-)$ group. Visceral fat area was assessed at the umbilical level using computed tomography.

\begin{tabular}{|c|c|c|c|c|c|}
\hline & $\begin{array}{l}\text { NAFLD }(-; n=15) \\
\quad 23 \%\end{array}$ & $\begin{array}{l}\text { NAFLD }(+; n=51) \\
\quad 77 \%\end{array}$ & $P$ value & $\begin{array}{l}\text { NASH }(n=14) \\
21 \%\end{array}$ & $P$ value \\
\hline Age (years) & $44.8 \pm 16.0$ & $48.1 \pm 18.0$ & & $44.6 \pm 6.4$ & \\
\hline $\operatorname{Sex}(M / F)$ & $\mathrm{M}: 5, \mathrm{~F}: 10$ & $M: 27, F: 24$ & & $\mathrm{M}: 6, \mathrm{~F}: 8$ & \\
\hline Male (\%) & 27 & 53 & & 43 & \\
\hline Onset $(\mathrm{AO} / \mathrm{CO})$ & $10 / 5$ & $32 / 19$ & & $8 / 6$ & \\
\hline $\mathrm{AO}(\%)$ & 66 & 63 & & 57 & \\
\hline Duration & $24.1 \pm 13.5$ & $19.3 \pm 12.2$ & 0.89 & $12.5 \pm 9.4$ & 0.20 \\
\hline IGF1 (ng/ml) & $55.3 \pm 31.9$ & $69.2 \pm 47.9$ & 0.36 & $51.7 \pm 13.5$ & 0.83 \\
\hline Cortisol replacement (mg/kg BW) & $0.24 \pm 0.16$ & $0.19 \pm 0.14$ & 0.28 & $0.20 \pm 0.04$ & 0.92 \\
\hline Gonadal replacement $(+/-)$ & $5 / 10$ & $15 / 36$ & 0.65 & $2 / 12$ & 0.13 \\
\hline BMI & $20.2 \pm 2.8$ & $26.0 \pm 4.8$ & $<0.005$ & $26.8 \pm 1.9$ & $<0.005$ \\
\hline Visceral fat area $\left(\mathrm{cm}^{2}\right)$ & $77.6 \pm 6.4$ & $175.0 \pm 42.0$ & $<0.05$ & $166.9 \pm 21.0$ & $<0.05$ \\
\hline AST (IU/I) & $26.8 \pm 15.0$ & $36.2 \pm 19.2$ & 0.11 & $56.6 \pm 9.9$ & $<0.005$ \\
\hline ALT (IU/I) & $23.4 \pm 17.6$ & $38.7 \pm 35.4$ & 0.13 & $72.0 \pm 7.7$ & $<0.0001$ \\
\hline$\gamma$-GTP (IU/I) & $38.1 \pm 42.5$ & $50.8 \pm 63.5$ & 0.50 & $121.8 \pm 48.1$ & $<0.05$ \\
\hline LDL-C (mg/dl) & $118.3 \pm 23.0$ & $131.0 \pm 29.1$ & 0.25 & $152.4 \pm 20.3$ & 0.06 \\
\hline HDL-C (mg/dl) & $75.9 \pm 30.5$ & $51.8 \pm 15.5$ & $<0.005$ & $45.6 \pm 9.5$ & 0.06 \\
\hline Triglyceride (mg/dl) & $162.2 \pm 88.7$ & $217.5 \pm 147.6$ & 0.21 & $351.8 \pm 102.1$ & $<0.01$ \\
\hline Fasting glucose (mg/dl) & $89.5 \pm 13.8$ & $93.5 \pm 9.8$ & 0.32 & $94.2 \pm 2.9$ & 0.48 \\
\hline Fasting IRI $(\mu \mathrm{U} / \mathrm{ml})$ & $2.5 \pm 1.0$ & $11.8 \pm 7.1$ & $<0.05$ & $14.2 \pm 3.8$ & $<0.05$ \\
\hline HOMA-IR & $0.46 \pm 0.30$ & $2.81 \pm 1.88$ & $<0.05$ & $3.36 \pm 0.98$ & $<0.05$ \\
\hline HbA1c (\%) & $5.18 \pm 0.35$ & $5.21 \pm 0.42$ & 0.86 & $5.18 \pm 0.17$ & 0.99 \\
\hline hs-CRP (ng/ml) & $0.26 \pm 0.37$ & $0.32 \pm 0.28$ & 0.67 & $0.43 \pm 0.18$ & 0.46 \\
\hline Hyaluronic acid (ng/ml) & $26.3 \pm 19.8$ & $29.3 \pm 20.1$ & 0.73 & $40.5 \pm 14.0$ & 0.31 \\
\hline Type IV collagen (ng/ml) & $3.4 \pm 0.5$ & $3.7 \pm 1.0$ & 0.36 & $4.6 \pm 0.7$ & $<0.05$ \\
\hline
\end{tabular}

Values in bold indicate statistical significance.

those in the NAFLD $(+)$ group (Supplementary Figure $1 \mathrm{~A}$ and $\mathrm{B}$, see section on supplementary data given at the end of this article). Comparison of the clinical characteristics demonstrated that BMI $(P<0.005)$, visceral fat area $(P<0.05)$, fasting IRI $(P<0.05)$, and HOMA-IR $(P<0.05)$ were significantly higher in the NAFLD $(+)$ group than in the NAFLD $(-)$ group. HDL-C levels were significantly lower in the NAFLD $(+)$ group $(P<0.005)$. In a subgroup of the NASH group, in addition to the parameters observed in the NAFLD group, triglyceride $(P<0.01)$ levels and a fibrotic marker for the liver, type IV collagen $(P<0.05)$ levels were significantly elevated compared with those in the NAFLD (-) group.

\section{The effect of GH replacement therapy on liver enzyme levels in patients with GHD}

Among the 66 GHD patients, we treated 19 patients who agreed with $\mathrm{GH}$ replacement therapy according to the guideline (13). Of these 19 patients, 11 patients were diagnosed with NAFLD $(+)$ and the remaining eight patients were NAFLD $(-)$. Interestingly, ALT $(P<0.001)$, AST $(P<0.005)$, and, $\gamma$-GTP $(P<0.05)$ levels after 6 months of $\mathrm{GH}$ replacement therapy were significantly decreased compared with their baseline levels (Fig. 1). The degree of improvement in the liver function was more predominant in the patients with elevated liver enzyme levels.

\section{The effect of GH replacement therapy on NASH in patients with GHD}

In this study, to quantitatively evaluate the effect of GH on histologically confirmed NASH, we analyzed five patients including the first reported one (6), who were treated with GH for 6-12 months and assessed biochemically (Fig. 2) and by liver biopsy (Fig. 3A) before and after the treatment. In addition to the liver enzyme levels (Supplementary Figure 2, see section on supplementary data given at the end of this article), the fibrotic markers, hyaluronic acid, and type IV collagen levels were significantly decreased during the $\mathrm{GH}$ therapy (Fig. 2). Based on the histological analysis, the steatosis $(P=0.04)$ and fibrosis $(P=0.04)$ scores in these patients were significantly improved after $\mathrm{GH}$ treatment (Fig. 3A and B).

\section{Discussion}

In the present study, we demonstrated that adult hypopituitary patients with GHD have a high prevalence of NAFLD. GH replacement therapy was effective for treating NAFLD/NASH in these patients, suggesting a physiological role of $\mathrm{GH}$ and IGF1 in the liver. Although the prevalence of NASH in the patients was obviously high as compared with the Japanese historical control subjects, it is suggested that the prevalence could be higher than that observed in this study because 

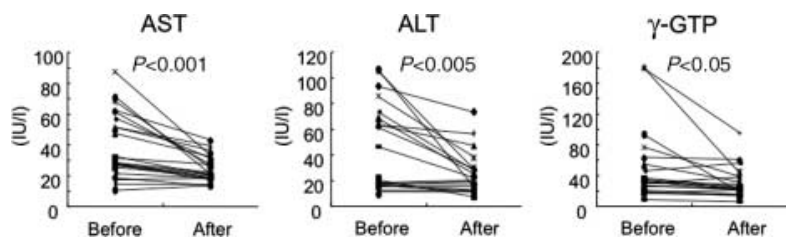

Figure 1 Serum aspartate aminotransferase and alanine aminotransferase, and $\gamma$-GTP concentrations before and after GH replacement therapy for 6 months in adult patients with GHD.

of the limited number of subjects in whom liver biopsy was undertaken. These data suggest that NAFLD/NASH is one of the important comorbidities in adult hypopituitary patients with GHD. Recently, Gardner et al. (26) reported that NAFLD is equally common in patients with GHD and age- and BMI-matched control subjects. Although the reason for the discrepancy is unknown, compared with the present study, the age of subjects was higher, the serum IGF1 levels were not severely impaired in the GHD group, and the unmatched sex in the study might influence the results. Moreover, as the authors discussed, although it was not statistically significant, GH replacement therapy showed a tendency to decrease liver fat content $(P=0.07)$, suggesting that the patient sample size might have been too small to detect the effect of GH.

Several factors, including race, age, gender, BMI, and diabetes, are known to affect an individual's susceptibility to NAFLD $(27,28)$. In hypopituitary adult patients with GHD, obesity is frequently observed particularly in the presence of hypothalamic dysfunction in craniopharyngioma (29). To exclude the effects of age, gender, and BMI, we enrolled healthy age-, gender-, and BMI-matched Japanese subjects as a control group in this study. Compared with this control group, the prevalence of NAFLD in hypopituitary patients with GHD was still significantly increased. These results indicate that the development of NAFLD may be independent of obesity. However, given that visceral obesity is predominant in the patients with adult GHD, it is possible that increased visceral fat may play a role in the development of NAFLD even in patients with the same BMI. The results that the NAFLD $(+)$ group in the patients with adult GHD exhibited higher visceral fat area than the NAFLD $(-)$ group rather indicated that visceral obesity is an important factor for the development of NAFLD in patients with GHD.

There are several factors that could affect the susceptibility of NAFLD besides age, gender, and BMI. An excess level of glucocorticoid is associated with visceral obesity and fatty liver (30). In our subjects, there were no significant differences in the dose of glucocorticoid replacement therapy in the patients with or without NAFLD (Table 3). Estrogen also plays an important role in the liver to modulate steatosis $(31,32)$. Indeed there was a clear gender difference in the prevalence of NAFLD in the control group (18\% in men vs $7 \%$ in women). Although we compared sex ratios and the gonadal hormone replacement therapy statuses in the GHD group, there were no significant differences (Supplementary Table 1, see section on supplementary data given at the end of this article). In contrast to the control group, there was no gender difference in the prevalence of NAFLD in the GHD group, suggesting that the status of sex hormones may be associated with the development of NAFLD; however, further analysis is necessary to clarify the involvement of sex hormones. We still cannot exclude the possibility that these hormone replacement therapies were not optimal and further investigation is necessary to elucidate the precise contribution of replacement therapy of these hormones.

We found that GH replacement therapy significantly decreased the liver enzyme levels in these patients. The improvement was observed as early as 2 months after the treatment (Supplementary Figure 2, see section on supplementary data given at the end of this article). The improvement of liver enzymes suggests that GH-deficient status was causally related to the liver dysfunction. Histological scoring showed that GH replacement therapy significantly improved NASH characteristics, particularly in the scoring of steatosis and fibrosis concomitant with a biochemical improvement of liver enzymes and a decrease in the fibrotic markers. Given that the other replacement therapies and antihyperlipidemic or antihypertensive agents were not changed during the GH replacement therapy and that NASH is generally progressive, it is speculated that these effects are directly attributable to the GH replacement therapy. However, considering the fact that even in subjects with metabolic syndrome without GHD, $\mathrm{GH}$ treatment has been shown to decrease the visceral adiposity and improve the metabolic parameters (33), we cannot exclude the possibility that these effects of $\mathrm{GH}$ in the liver were exerted as pharmacological actions via its lipolytic effect.

With regard to the mechanistic action of $\mathrm{GH}$, it has been shown that specific deletion of GH receptor (GHR) in hepatocytes leads to steatosis with an impaired lipid metabolism (34). Furthermore, liver-specific deletion of JAK2 $(35)$ or STAT5 $(36,37)$ in mice results in steatosis, suggesting the importance of downstream signaling of GHR in the lipid metabolism of the hepatocytes. In an
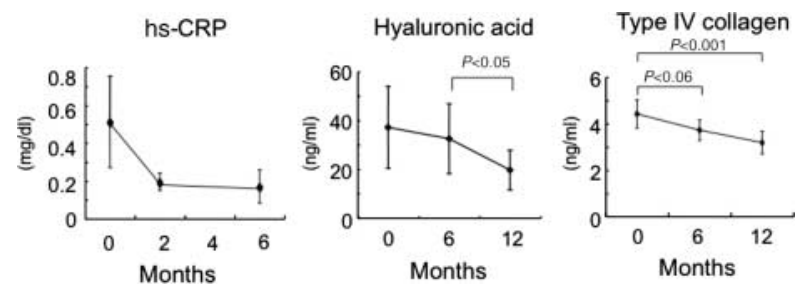

Figure 2 Changes in inflammation and fibrotic markers in the serum of NASH patients during GH therapy. Plus-minus values are means \pm S.D. 
A

Before

Case 1

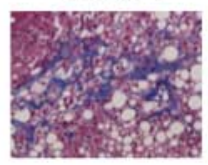

After

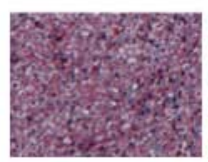

Case 2
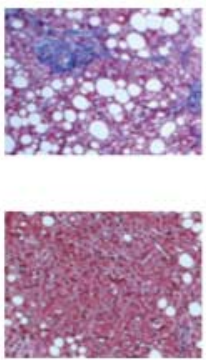

Case 3
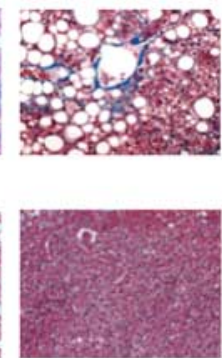

Case 4
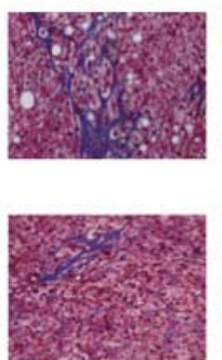

Case 5
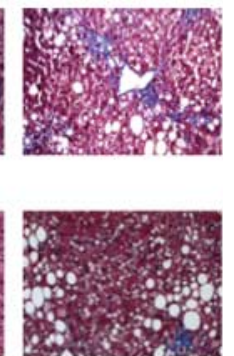

B
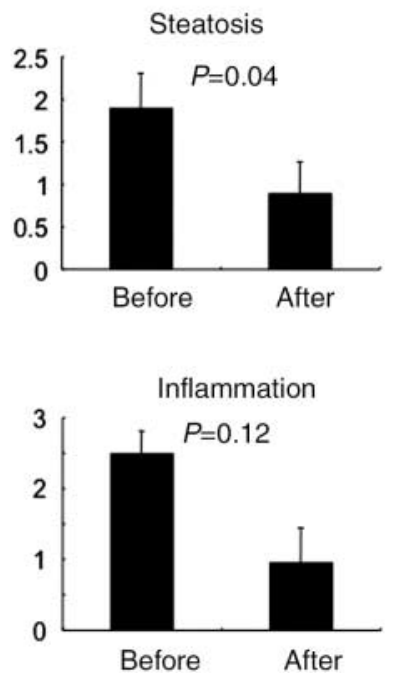
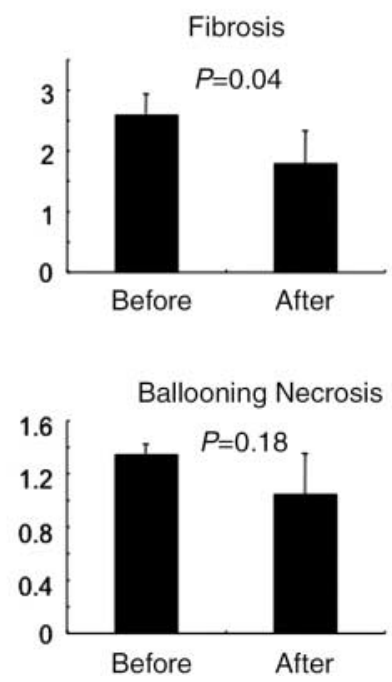

Figure 3 (A) Histological analysis by Masson's trichrome staining of the liver before and after $\mathrm{GH}$ replacement therapy in NASH patients with GHD (cases 1-5 in Table 2). The fibrotic changes were visualized with blue staining. (B) Mean scores for steatosis, fibrosis, inflammation, and ballooning necrosis in liver biopsy specimens assessed using the NAFLD activity score. animal model of liver cirrhosis, exogenous IGF1 expression in the liver reduced fibrosis and ultimately led to amendment of cirrhosis, suggesting an antifibrotic action of IGF1 (38). GH also has a pronounced lipolytic effect, particularly in the visceral fat (39). Because visceral adiposity is closely related to development of NAFLD, it is plausible that GH exerts its effect by reducing the visceral fat as an indirect mechanism. Collectively, these findings suggest that direct, indirect, and plural actions of GH and IGF1 are closely interrelated and contribute to occurrence of NAFLD.

Among the patients with GHD, visceral fat area was significantly increased in NAFLD (+) patients but not in NAFLD $(-)$ patients. Also, fasting IRI and HOMA-IR were significantly increased in NAFLD $(+)$ patients. These results are in line with the data that the pathogenesis of general NASH is closely related to visceral obesity and insulin resistance (11). However, comparing the BMI-matched control subjects, the susceptibility to NAFLD was increased in patients with GHD. One possible mechanism for this increased susceptibility could be enhanced inflammation and oxidative stress levels in patients with GHD as the second hit in the development of NAFLD (11). hs-CRP and interleukin 6 levels were elevated in adult patients with GHD, and GH replacement therapy decreased the levels of these markers (40). Intriguingly, lower IGF1 status is associated with higher CRP and hepatic steatosis in obese women, suggesting an important role of IGF1 in the regulation of inflammation (41).

The limitations of this study are that it was retrospective, included a small number of study subjects, liver biopsies were only done in a small subset of the study subjects, and there was no control group in the study for $\mathrm{GH}$ treatment. In addition, the underlying mechanisms, which explain the role of GH in the liver, remain unclarified. Nevertheless, the comparison between age-, gender-, and BMI-matched control and the hypopituitary patients with GHD in this study clearly showed the high prevalence of NAFLD in the patients.

In conclusion, adult hypopituitary patients with GHD had a high prevalence of NAFLD. GH replacement therapy was effective for treating NAFLD/NASH in these patients. Because NASH is a progressive disease with a poor prognosis, clinical assessment for NAFLD/NASH in hypopituitary patients with GHD as the comorbidity is warranted. 


\section{Supplementary data}

This is linked to the online version of the paper at http://dx.doi.org/10. 1530/EJE-12-0252.

\section{Declaration of interest}

The authors declare that there is no conflict of interest that could be perceived as prejudicing the impartiality of the research reported.

\section{Funding}

This work was supported in part by a Grant-in-Aid for Scientific Research from the Japanese Ministry of Education, Culture, Sports, Science, and Technology 19591077 and 70301281 and in part by Grants-in-Aid for Scientific Research (research on hypothalamichypophyseal disorders) from the Ministry of Health, Labor, and Welfare, Japan.

\section{Acknowledgements}

We thank Drs S Seino, W Ogawa, K Sakaguchi, Y Hirota, N Hashimoto, Y Inoue, T Matsuda, S Yoshioka, K Takahashi, $\mathrm{T}$ Saibara and $\mathrm{H}$ Iwakabe for their support and discussion and C Ogata and K Imura for their excellent technical assistance.

\section{References}

1 Thomas JD \& Monson JP. Adult GH deficiency throughout lifetime. European Journal of Endocrinology 2009161 (Suppl 1) S97-S106. (doi:10.1530/EJE-09-0258)

2 Adams LA, Feldstein A, Lindor KD \& Angulo P. Nonalcoholic fatty liver disease among patients with hypothalamic and pituitary dysfunction. Hepatology 200439 909-914. (doi:10.1002/hep. 20140)

3 Kaji H, Sakurai T, Iguchi G, Murata M, Kishimoto M, Yoshioka S, Iida K, Okimura Y \& Chihara K. Adult growth hormone deficiency in Japan: results of investigation by questionnaire. Endocrine Journal 200249 597-604. (doi:10.1507/endocrj.49.597)

4 Fukuda I, Hizuka N, Yasumoto K, Morita J, Kurimoto M \& Takano K. Metabolic co-morbidities revealed in patients with childhood-onset adult GH deficiency after cessation of $\mathrm{GH}$ replacement therapy for short stature. Endocrine Journal 2008 55 977-984. (doi:10.1507/endocrj.K08E-079)

5 Ichikawa T, Hamasaki K, Ishikawa H, Ejima E, Eguchi K \& Nakao K. Non-alcoholic steatohepatitis and hepatic steatosis in patients with adult onset growth hormone deficiency. Gut 2003 52 914. (doi:10.1136/gut.52.6.914)

6 Takahashi Y, Iida K, Takahashi K, Yoshioka S, Fukuoka H, Takeno R, Imanaka M, Nishizawa H, Takahashi M, Seo Y, Hayashi Y, Kondo T, Okimura Y, Kaji H, Kitazawa R, Kitazawa S \& Chihara K. Growth hormone reverses nonalcoholic steatohepatitis in a patient with adult growth hormone deficiency. Gastroenterology 2007132 938-943. (doi:10.1053/j.gastro. 2006.12.024)

7 Hong JW, Kim JY, Kim YE \& Lee EJ. Metabolic parameters and nonalcoholic fatty liver disease in hypopituitary men. Hormone and Metabolic Research 201143 48-54. (doi:10.1055/s-00301265217)

8 Ichikawa T, Nakao K, Hamasaki K, Furukawa R, Tsuruta S, Ueda Y, Taura N, Shibata H, Fujimoto M, Toriyama K \& Eguchi K. Role of growth hormone, insulin-like growth factor 1 and insulin-like growth factor-binding protein 3 in development of non-alcoholic fatty liver disease. Hepatology International $2007 \mathbf{1}$ 287-294. (doi:10.1007/s12072-007-9007-4)
9 Tarantino G, Savastano S \& Colao A. Hepatic steatosis, low-grade chronic inflammation and hormone/growth factor/adipokine imbalance. World Journal of Gastroenterology 201016 4773-4783. (doi:10.3748/wjg.v16.i38.4773)

10 Angulo P \& Lindor KD. Non-alcoholic fatty liver disease. Journal of Gastroenterology and Hepatology 200217 S186-S190. (doi:10. 1046/j.1440-1746.17.s1.10.x)

11 Adams LA \& Angulo P. Recent concepts in non-alcoholic fatty liver disease. Diabetic Medicine 200522 1129-1133. (doi:10.1111/ j.1464-5491.2005.01748.x)

12 Nilsson AG, Svensson J \& Johannsson G. Management of growth hormone deficiency in adults. Growth Hormone \& IGF Research 200717 441-462. (doi:10.1016/j.ghir.2007.05.005)

13 Molitch ME, Clemmons DR, Malozowski S, Merriam GR, Shalet SM, Vance ML \& Stephens PA. Evaluation and treatment of adult growth hormone deficiency: an Endocrine Society Clinical Practice Guideline. Journal of Clinical Endocrinology and Metabolism 200691 1621-1634. (doi:10.1210/jc.2005-2227)

14 Chihara K, Shimatsu A, Hizuka N, Tanaka T, Seino Y \& Katofor Y. A simple diagnostic test using GH-releasing peptide-2 in adult GH deficiency. European Journal of Endocrinology 2007 157 19-27. (doi:10.1530/EJE-07-0066)

15 Tomlinson JW, Holden N, Hills RK, Wheatley K, Clayton RN, Bates AS, Sheppard MC \& Stewart PM. Association between premature mortality and hypopituitarism. West Midlands Prospective Hypopituitary Study Group. Lancet 2001357 425-431. (doi:10.1016/S0140-6736(00)04006-X)

16 Belfort R, Harrison SA, Brown K, Darland C, Finch J, Hardies J, Balas B, Gastaldelli A, Tio F, Pulcini J, Berria R, Ma JZ, Dwivedi S, Havranek R, Fincke C, DeFronzo R, Bannayan GA, Schenker S \& Cusi K. A placebo-controlled trial of pioglitazone in subjects with nonalcoholic steatohepatitis. New England Journal of Medicine 2006 355 2297-2307. (doi:10.1056/NEJMoa060326)

17 Charatcharoenwitthaya $\mathrm{P}$ \& Lindor KD. Role of radiologic modalities in the management of non-alcoholic steatohepatitis. Clinics in Liver Disease 200711 37-54, viii. (doi:10.1016/j.cld. 2007.02.014)

18 Sanyal AJ. AGA technical review on nonalcoholic fatty liver disease. Gastroenterology 2002123 1705-1725. (doi:10.1053/ gast.2002.36572)

19 Yajima Y, Ohta K, Narui T, Abe R, Suzuki H \& Ohtsuki M. Ultrasonographical diagnosis of fatty liver: significance of the liver-kidney contrast. Tohoku Journal of Experimental Medicine 1983139 43-50. (doi:10.1620/tjem.139.43)

20 Adams LA \& Talwalkar JA. Diagnostic evaluation of nonalcoholic fatty liver disease. Journal of Clinical Gastroenterology $2006 \mathbf{4 0}$ (Suppl 1) S34-S38.

21 Kleiner DE, Brunt EM, Van Natta M, Behling C, Contos MJ, Cummings OW, Ferrell LD, Liu YC, Torbenson MS, Unalp-Arida A, Yeh M, McCullough AJ \& Sanyal AJ. Design and validation of a histological scoring system for nonalcoholic fatty liver disease. Hepatology 200541 1313-1321. (doi:10.1002/hep.20701)

22 Kojima S, Watanabe N, Numata M, Ogawa T \& Matsuzaki S. Increase in the prevalence of fatty liver in Japan over the past 12 years: analysis of clinical background. Journal of Gastroenterology 200338 954-961. (doi:10.1007/s00535-003-1178-8)

23 Yoshiike N \& Lwin H. Epidemiological aspects of obesity and NASH/NAFLD in Japan. Hepatology Research 200533 77-82. (doi:10.1016/j.hepres.2005.09.008)

24 Ono M \& Saibara T. Clinical features of nonalcoholic steatohepatitis in Japan: evidence from the literature. Journal of Gastroenterology 200641 725-732. (doi:10.1007/s00535-006-1876-0)

25 Hashimoto E \& Tokushige K. Prevalence, gender, ethnic variations, and prognosis of NASH. Journal of Gastroenterology $2011 \mathbf{4 6}$ (Suppl 1) 63-69. (doi:10.1007/s00535-010-0311-8)

26 Gardner CJ, Irwin A, Daousi C, Macfarlane I, Joseph F, Bell J, Thomas EL, Adams V. Kemp G \& Cuthbertson DJ. Non alcoholic fatty liver disease, growth hormone deficiency and the effects of growth hormone replacement: a LIVERpool magnetic resonance spectroscopy study. European Journal of Endocrinology 2012166 993-1002. (doi:10.1530/EJE-12-0002) 
27 Perlemuter G, Bigorgne A, Cassard-Doulcier AM \& Naveau S. Nonalcoholic fatty liver disease: from pathogenesis to patient care. Nature Clinical Practice Endocrinology \& Metabolism 20073 458-469. (doi:10.1038/ncpendmet0505)

28 Adams LA, Angulo P \& Lindor KD. Nonalcoholic fatty liver disease. CMAJ: Canadian Medical Association Journal 2005172 899-905. (doi:10.1503/cmaj.045232)

29 Muller HL. Childhood craniopharyngioma - current concepts in diagnosis, therapy and follow-up. Nature Reviews Endocrinology 20106 609-618. (doi:10.1038/nrendo.2010.168)

30 Rockall AG, Sohaib SA, Evans D, Kaltsas G, Isidori AM, Monson JP, Besser GM, Grossman AB \& Reznek RH. Hepatic steatosis in Cushing's syndrome: a radiological assessment using computed tomography. European Journal of Endocrinology 2003149 543-548. (doi:10.1530/eje.0.1490543)

31 Angulo P. Nonalcoholic fatty liver disease. New England Journal of Medicine 2002346 1221-1231. (doi:10.1056/NEJMra $011775)$

32 Osman KA, Osman MM \& Ahmed MH. Tamoxifen-induced nonalcoholic steatohepatitis: where are we now and where are we going? Expert Opinion on Drug Safety 20076 1-4. (doi:10.1517/ 14740338.6.1.1)

33 Johannsson G, Marin P, Lonn L, Ottosson M, Stenlof K, Bjorntorp P, Sjostrom L \& Bengtsson BA. Growth hormone treatment of abdominally obese men reduces abdominal fat mass, improves glucose and lipoprotein metabolism, and reduces diastolic blood pressure. Journal of Clinical Endocrinology and Metabolism $1997 \mathbf{8 2}$ 727-734. (doi:10.1210/jc.82.3.727)

34 Fan Y, Menon RK, Cohen P, Hwang D, Clemens T, DiGirolamo DJ, Kopchick JJ, Le Roith D, Trucco M \& Sperling MA. Liver-specific deletion of the growth hormone receptor reveals essential role of growth hormone signaling in hepatic lipid metabolism. Journal of Biological Chemistry 2009284 19937-19944. (doi:10.1074/jbc. M109.014308)

35 Sos BC, Harris C, Nordstrom SM, Tran JL, Balazs M, Caplazi P, Febbraio M, Applegate MA, Wagner KU \& Weiss EJ. Abrogation of growth hormone secretion rescues fatty liver in mice with hepatocyte-specific deletion of JAK2. Journal of Clinical Investigation 2011121 1412-1423. (doi:10.1172/JCI42894)
36 Cui Y, Hosui A, Sun R, Shen K, Gavrilova O, Chen W, Cam MC, Gao B, Robinson GW \& Hennighausen L. Loss of signal transducer and activator of transcription 5 leads to hepatosteatosis and impaired liver regeneration. Hepatology $2007 \mathbf{4 6}$ 504-513. (doi:10.1002/hep.21713)

37 Barclay JL, Nelson CN, Ishikawa M, Murray LA, Kerr LM, McPhee TR, Powell EE \& Waters MJ. GH-dependent STAT5 signaling plays an important role in hepatic lipid metabolism. Endocrinology 2011152 181-192. (doi:10.1210/en.2010-0537)

38 Sobrevals L, Rodriguez C, Romero-Trevejo JL, Gondi G, Monreal I, Paneda A, Juanarena N, Arcelus S, Razquin N, Guembe L, Gonzalez-Aseguinolaza G, Prieto J \& Fortes P. Insulin-like growth factor I gene transfer to cirrhotic liver induces fibrolysis and reduces fibrogenesis leading to cirrhosis reversion in rats. Hepatology 201051 912-921.

39 Gravholt $\mathrm{CH}$, Schmitz O, Simonsen L, Bulow J, Christiansen JS \& Moller N. Effects of a physiological GH pulse on interstitial glycerol in abdominal and femoral adipose tissue. American Journal of Physiology 1999277 E848-E854.

40 Sesmilo G, Biller BM, Llevadot J, Hayden D, Hanson G, Rifai N \& Klibanski A. Effects of growth hormone administration on inflammatory and other cardiovascular risk markers in men with growth hormone deficiency. A randomized, controlled clinical trial. Annals of Internal Medicine 2000133 111-122.

41 Savastano S, Di Somma C, Pizza G, De Rosa A, Nedi V, Rossi A, Orio F, Lombardi G, Colao A \& Tarantino G. Liver-spleen axis, insulin-like growth factor-(IGF)-I axis and fat mass in overweight/ obese females. Journal of Translational Medicine 20119136. (doi:10.1186/1479-5876-9-136)

42 Matthews DR, Hosker JP, Rudenski AS, Naylor BA, Treacher DF \& Turner RC. Homeostasis model assessment: insulin resistance and beta-cell function from fasting plasma glucose and insulin concentrations in man. Diabetologia 198528 412-419. (doi:10. 1007/BF00280883)

Received 20 March 2012

Revised version received 13 April 2012

Accepted 24 April 2012 